Research Article

\title{
Assess the Impact of a Structured Teaching Programme on Awareness of Malnutrition and its Prevention among Mothers of Children under the Age of Five in a Specific Area of Lingiadih Village, Bilaspur (C.G.)
}

\author{
Shailvina D Masih', Linson $\mathrm{CC}^{2}$ \\ ${ }^{1}$ Dr Sarvapalli Radhakrishnan (SRK) University, Bhopal (MP), India. \\ 2JOSCO, Mangalore. \\ DOI: https://doi.org/10.24321/2348.2133.202005
}

\section{I $\quad \mathbf{N} \quad \mathbf{F} \quad \mathbf{O}$}

\section{Corresponding Author:}

Shailvina D Masih, Dr Sarvapalli Radhakrishnan (SRK) University, Bhopal (MP), India.

E-mail Id:

masihshailvina@gmail.com

Orcid Id:

https://orcid.org/0000-0002-9177-8680

How to cite this article:

Masih SD, Linson CC. Assess the Impact of a Structured Teaching Programme on Awareness of Malnutrition and its Prevention among Mothers of Children under the Age of Five in a Specific Area of Lingiadih Village, Bilaspur (C.G.). Ind J Holist Nurs 2020; 11(4): 5-11.

Date of Submission: 2020-12-25

Date of Acceptance: 2020-12-29

\section{$\begin{array}{llllllll}\mathbf{A} & \mathbf{B} & \mathbf{S} & \mathbf{T} & \mathbf{R} & \mathbf{A} & \mathbf{C} & \mathbf{T}\end{array}$}

Background: The mother is the sole provider of primary care for her child for the first five years of his or her life. Her ability to provide treatment is primarily dictated by her knowledge and understanding of basic nutrition and health care. The numbers would improve dramatically if mothers were made more aware of infant feeding strategies and other healthcare practices.

Objective: To assess the impact of a structured teaching programme on the awareness of malnutrition and its prevention among mothers of children under the age of five in a specific area of Lingiadih Village, Bilaspur (C.G.).

Method: The convenient sampling technique was used in the study.

Result and Conclusion: The findings show that about $58 \%$ of the mothers of under-five children were in the age group of $21-25$ years, $58 \%$ were Hindus, 52\% were taking a mixed diet, $76 \%$ were from nuclear families, $62 \%$ had a family income of INR $1000-3000$ per month, 50\% took primary education, $92 \%$ had one child in the family, $88 \%$ of the children were partially immunized, and $30 \%$ of the mothers got the information about malnutrition from mass media.

7 (14\%) mothers had average knowledge, 43 (86\%) had bad knowledge, and $0(0 \%)$ had good knowledge, according to the assessment of the overall pre-test knowledge level of the mothers of under-five children regarding prevention of protein-energy malnutrition.

The overall post-test awareness assessment showed that structured teaching programme proved to be significantly effective in improving the knowledge of mothers of under-five children regarding the prevention of protein-energy malnutrition. The study concluded that there was significant difference between knowledge score and selected demographic variables hence $\mathrm{HO}$ was rejected.

Keywords: Assess, Impact, Structured Teaching Programme, Knowledge, Malnutrition, Prevention 


\section{Introduction}

"How wonderful it is that nobody need wait a single moment before starting to improve the world"

Anne Frank

Today's healthy child is tomorrow's better citizen. The development of a healthy child is influenced by many factors. Under-five children form the most vulnerable group of children who are prone to many infective diseases and nutritional deficiencies.

Children are the future pillars of a nation. The nutrition of these children would determine the strength of tomorrow's nation. Inadequate nutrition of these children leads to retarded growth and development and may cripple the child for life. In a developing country like India, there are many constraints to better living and adequate nutrition, lack of awareness about the dietary requirements and nutritive value of different food are the main causes of prevailing malnutrition among preschool children.

Overall, nearly half of the young children in India are underweight (46\%) and one in six children were wasted (16\%). The levels of undernutrition are much higher in rural areas than in urban areas. Undernutrition is the most prominent in the states of Bihar, Uttar Pradesh, Madhya Pradesh, and Rajasthan. About half of the children in Assam and Haryana are stunted. In the remote areas, a total of 20.3 per cent of children were seriously malnourished, 30.2 per cent were moderately malnourished, and 50.5 per cent were severely malnourished (moderate and severe). In the city, $12 \%$ of the children were seriously malnourished, $27 \%$ were moderately malnourished, and 39\% were malnourished (moderate and severe). Malnutrition was much more prevalent among tribal children.

Children under the age of five years are the hardest on a global scale. The five nutritional deficiency diseases that are being accorded the highest priority action are kwashiorkor, marasmus, xeropthalmia, nutritional anaemia, and endemic goitre. Malnutrition is preventable when tried well in advance; improving mother's educational levels and providing mothers with the information that they need on children care are the important components of a strategy to improve nutrition.

So the investigator felt the need for a study to assess the knowledge of mothers of under-five children regarding nutrition. The Investigator was of the opinion that a structured teaching programme can guide the mothers to improve their knowledge.

\section{Need of the Study}

Infants and children under five constitute the most vulnerable group. They are seriously affected by the deficiency of protein. Proteins are very important for growth and development, wear and tear of tissue repair and maintenance, formation of immune bodies, enzymes and hormones. Proteins also act as sources of energy when consumed in excess of the body need. Protein sources are basically classified as animal sources (e.g., cheese, milk, liver, fish, cakes, and seaweeds meat, and eggs), plant sources (e.g., pulses, nuts, beans and soya beans), and conventional sources (e.g., oilseeds, Advanced malnutrition can cause serious complications further leading to superadded overt and hidden infections like septicemia, pneumonia, diarrhoea, pyoderma, scabies, U.T.I., and tuberculosis. Mothers are the most wondrous caregivers who nurture their kids, thus they play a prime role in providing nutrition, and hence they should have adequate knowledge of the significance of protein in the diet of under-five children.

Ongoing health education and reinforcement while monitoring to reduce protein deficiency is an important challenge for nurses. Educating the mothers is the process of providing them assistance to learn and incorporate healthy eating habits in everyday life. Providing sound and sincere advice regarding the measures for the adequate intake of protein will definitely lead to health promotion. Hence the investigator found the need to assess the knowledge of mothers regarding giving a protein-rich diet to the underfive children.

\section{Objectives of the Study}

- $\quad$ To assess the pre-test score on knowledge regarding malnutrition and its prevention among the mothers of under-five children in the selected area of Lingiadih Village, Bilaspur (C.G.)

- To formulate and provide a structured teaching programme regarding malnutrition and its prevention to the mothers of under-five children in the selected area of Lingiadih Village, Bilaspur (C.G.)

- $\quad$ To assess the post-test score on knowledge regarding malnutrition and its prevention among the mothers of under-five children in the selected area of Lingiadih Village, Bilaspur (C.G.)

- To find out the association between the pre-test and post-test knowledge score regarding malnutrition and its prevention among the mothers of under-five children in the selected area of Lingiadih Village, Bilaspur (C.G.)

\section{Hypothesis}

- $\mathrm{H}_{0}$ : There will be no significant difference between knowledge score and selected demographic variables.

- $\mathrm{H}_{1}$ : There will be a significant difference between the pre-test and post-test knowledge scores of the mothers of under-five children.

- $\mathrm{H}_{2}$ : There will be a significant association between knowledge score and selected demographic variables. 


\section{Assumptions}

- The mothers will have less knowledge of malnutrition and its prevention before the administration of the structured teaching programme

- The structured teaching programme will enhance the knowledge of mothers of under-five children regarding malnutrition and its prevention

- The difference in knowledge will show the effectiveness of the structured teaching programme

- Demographic factors will have an influence on the knowledge score

\section{Material and Methodology}

\section{Research Approach}

Quantitative research approach.

\section{Research Design}

Pre-experimental research design.

\section{Setting}

The study was conducted in a selected area of Lingiadih Village, Bilaspur (C.G.).

\section{Data Collection Period}

The data was collected from $15 / 11 / 20$ to $15 / 12 / 20$.

\section{Population}

- Accessible population: All mothers having under-five children who meet the inclusion criteria and are staying in the selected area of Lingiadih Village, Bilaspur (C.G.)

- Target population: Mothers having under-five children staying in the selected area of Lingiadih Village, Bilaspur (C.G.)

\section{Criteria for Sample Selection}

\section{Inclusion Criteria}

This study included only:

- Mothers who had under-five children

- Mothers who were willing to participate in the study

- Mothers who were present at the time of the study

\section{Exclusion Criteria}

The following were not included in the study:

- Mothers who did not have under-five children

- Mothers who have already undergone any interventional programme for the prevention of malnutrition

\section{Sample Selection}

Sample Size: The sample size of the study was 50 mothers having under-five children.

Sample Technique: The research study was conducted by non-probability purposive sampling technique.

\section{Variables}

Independent Variables: Mother's age, religion, diet pattern, type of family, family income, educational status, number of children, immunization status of under-five children, and source of information.

Dependent Variables: Knowledge of mothers of underfive children.

Data Analysis and Interpretation: The collected data were analysed using both descriptive and inferential statistics.

\section{Procedure for Data Collection}

Before the collection of data, formal written consent was obtained from the mothers of under-five children. Data collection was done by using a structured questionnaire.

\section{Development and Description Of Tool}

A structured knowledge questionnaire was used to assess the knowledge of mothers of children under the age of five years regarding malnutrition. The structured questionnaire consisted of:

Part A: Demographic variables

Part B: Structured questionnaire on knowledge regarding malnutrition and its prevention

\section{Result}

Section A: Demographic data were analysed using frequency and percentage which is shown as follows.

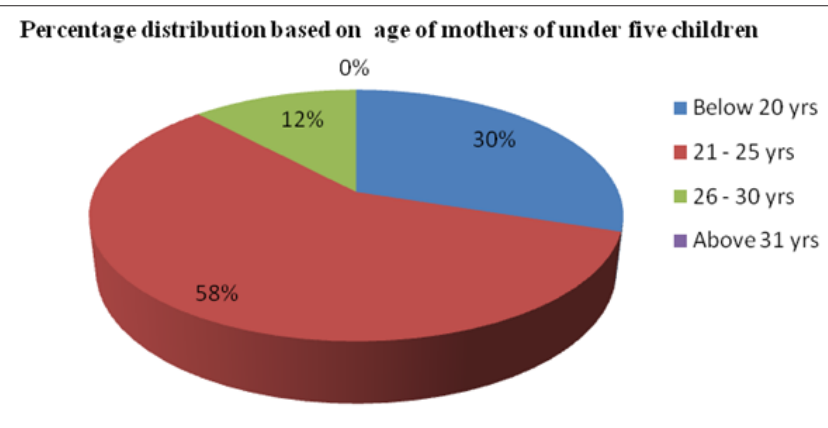

Figure I.Percentage Distribution based on Age of Mothers of Under-five Children

Percentage distribution based on Religion of mothers of under five children

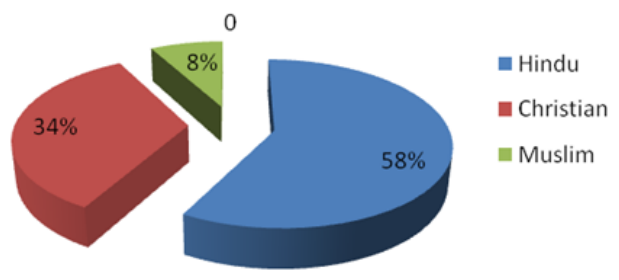

Figure 2.Percentage Distribution based on Religion of Mothers of Under-five Children 


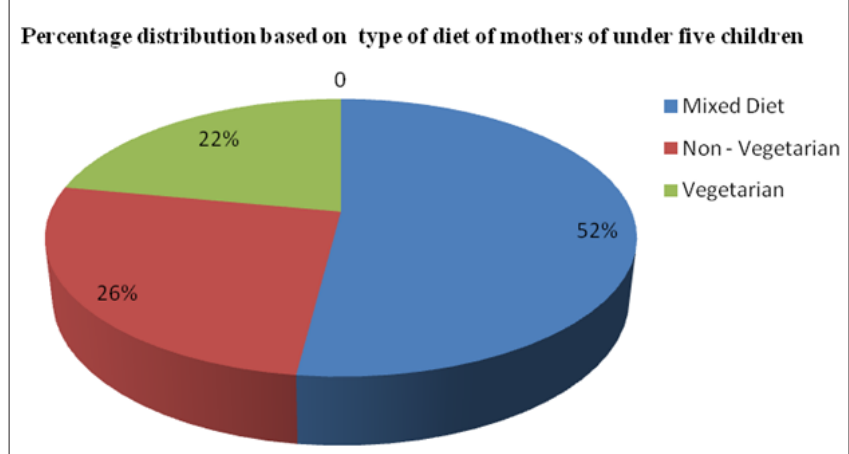

Figure 3.Percentage Distribution based on the Type of Diet of Mothers of Under-five Children

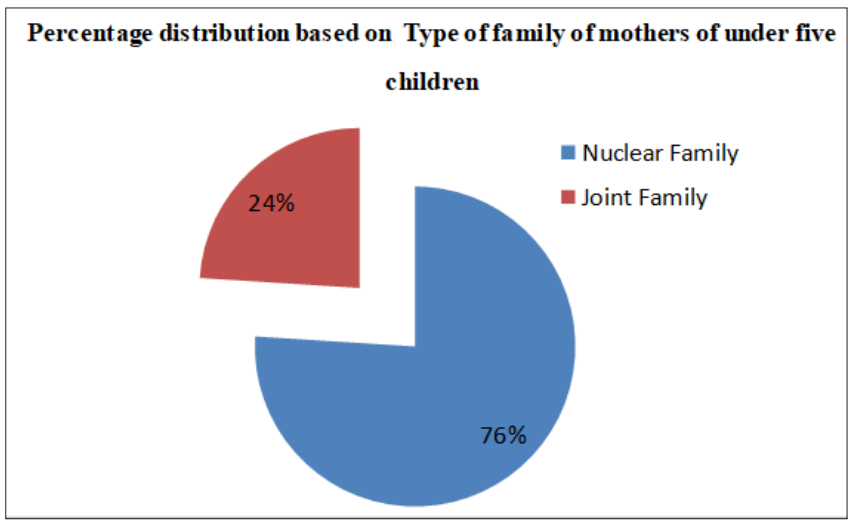

Figure 4.Percentage Distribution based on Type of Family of Mothers of Under-five Children

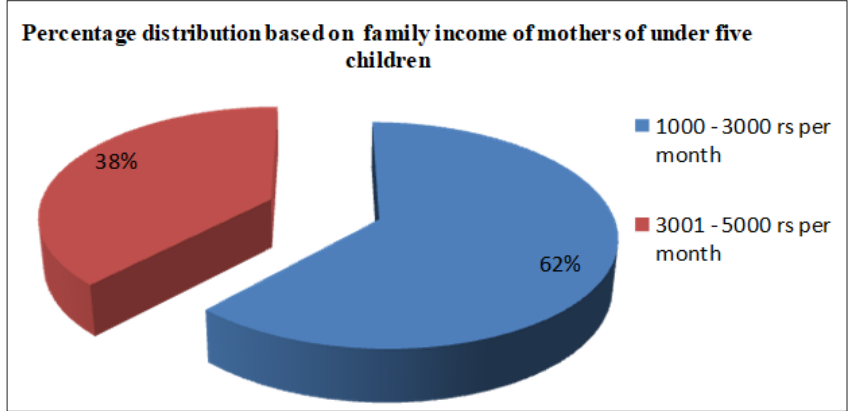

Figure 5.Percentage Distribution based on Family Income of Mothers of Under-five Children

Percentage distribution based on EducationalQualification of mothers of

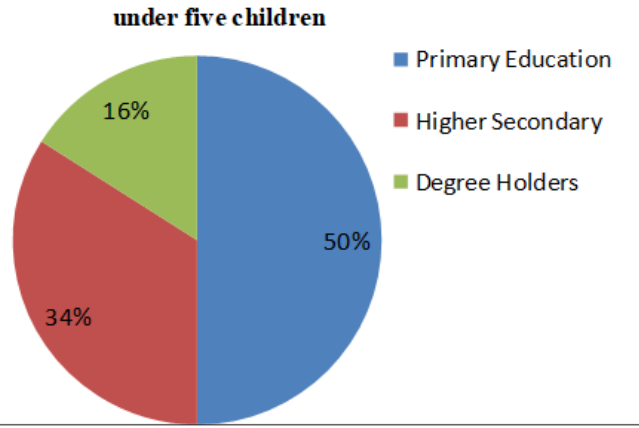

Figure 6.Percentage Distribution based on Educational Qualification of Mothers of under-five Children

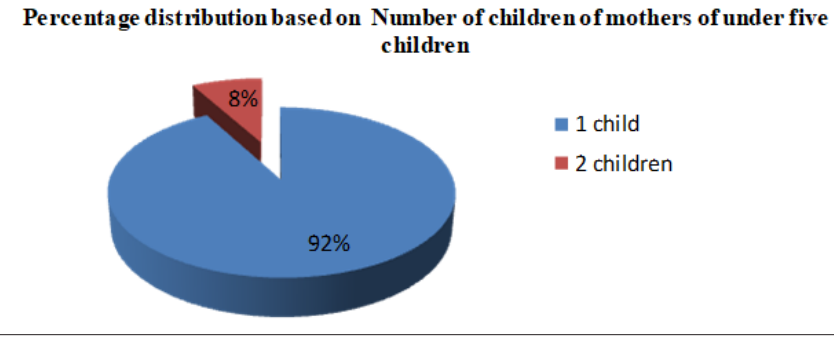

Figure 7.Percentage Distribution based on Number of Children of Mothers of Under-five Children

Percentage distribution ba sed on immunization status of children of mothers of under five children

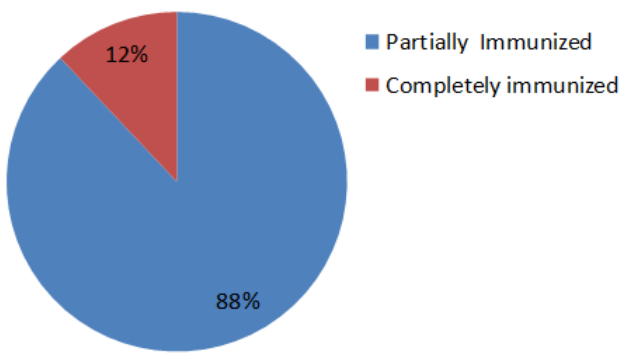

Figure 8.Percentage Distribution based on Immunization Status of Children of Mothers of Under-five Children

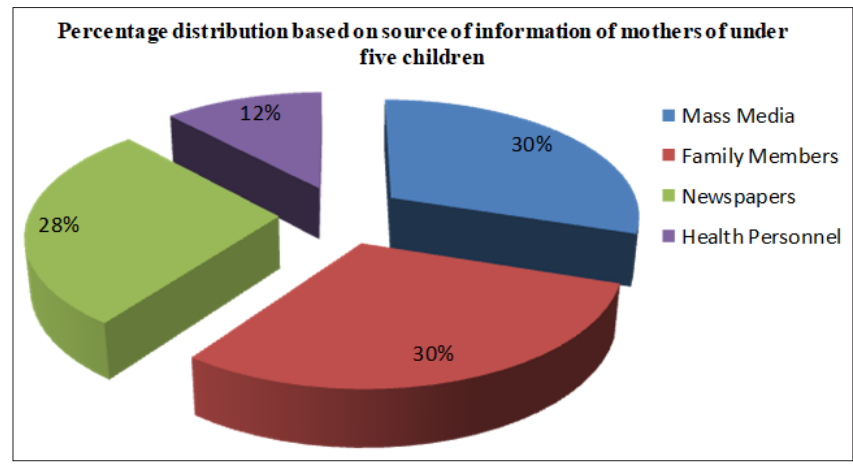

Figure 9.Percentage Distribution based on Source of Information of Mothers of Under-five Children

Section B: This section deals with the criteria-wise analysis of pre-test and post-test knowledge score of the prevention of protein-energy malnutrition among mothers of underfive children.

\section{Assessment of Overall Pre-test and Post-test Knowledge Score}

It was found that 7 (14\%) mothers had average knowledge, $43(86 \%)$ had bad knowledge, and $0(0 \%)$ had good knowledge, according to the assessment of overall pretest knowledge level of mothers of under-five children regarding the prevention of protein-energy malnutrition. The overall post-test awareness level of mothers of children under the age of five years about protein-energy prevention was assessed, and it was found that $100 \%$ of the mothers had moderately adequate knowledge. 
Table I.Analysis of Pre-test and Post-test Knowledge Score of the Prevention of Protein-energy Malnutrition among Mothers of Under-five Children

\begin{tabular}{|c|c|c|c|c|c|}
\hline \multirow{2}{*}{ S. No. } & \multirow{2}{*}{ Knowledge Score } & \multicolumn{2}{|c|}{ Pre-Test Score } & \multicolumn{2}{c|}{ Post-Test Score } \\
\cline { 3 - 6 } & & Frequency & Percentage & Frequency & Percentage \\
\hline 1. & Good Knowledge & 0 & 0 & 0 & 0 \\
\hline 2. & Average Knowledge & 7 & 14 & 50 & 100 \\
\hline 3. & Poor Knowledge & 43 & 86 & 0 & 0 \\
\hline & Total & 50 & 100 & 50 & 100 \\
\hline
\end{tabular}

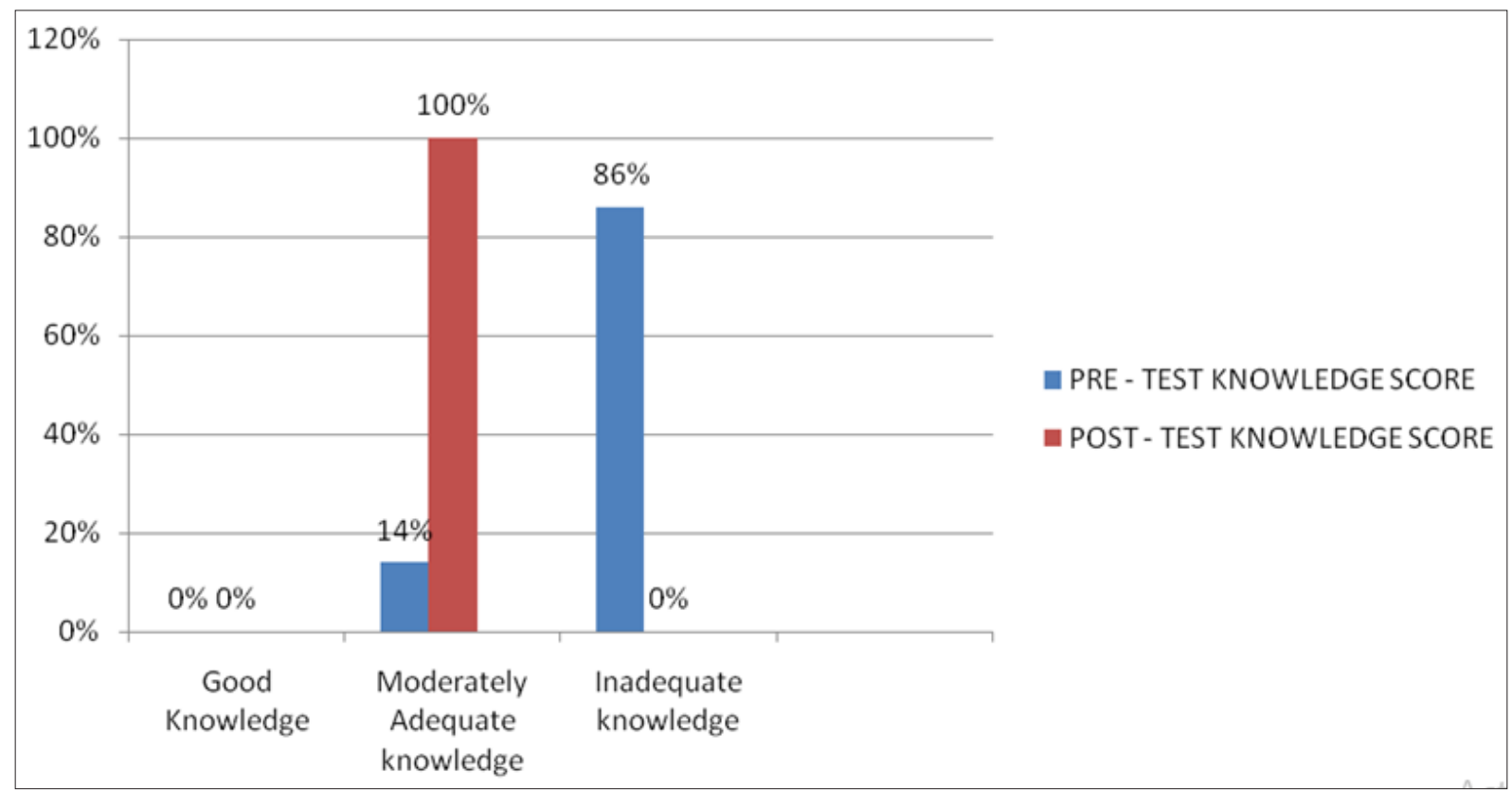

Figure 10.Percentage Distribution based on Pre-Test and Post-Test Knowledge Score of Mothers of Under-five Children

Section C: This section deals with the analysis of data related to the effectiveness of planned teaching programme knowledge regarding the prevention of protein-energy malnutrition among the mothers of under-five children in the selected rural community.

To compare the comprehension scores of the mothers of children under the age of five years and to determine the efficacy of a proposed teaching programme, the researcher used a paired t-test. In the pre-test, the average intelligence score was 8.96, with a standard deviation of 1.32, and in the post-test, it was 13.38 , with a standard deviation of 1.81. The t-value for this relationship was 15.95 , and the p-value was 0.00 .

The association between the demographic variables and the pre-test knowledge was determined with the help of a chi-square test. The $p$-value of the association test with knowledge was found to be greater than 0.05 , for all the demographic variables.

Table 2.Chi-square Value showing the Effectiveness of Planned Teaching Programme Knowledge regarding the Prevention of Protein-energy Malnutrition among the Mothers of Under-five Children in the Selected Rural Community

\begin{tabular}{|r|c|c|c|c|c|}
\hline “t” Test & Mean & Standard deviation & D.F. & Calculated 't'-value & Significance \\
\cline { 1 - 3 } Pre-test & 8.96 & \pm 1.32 & 99 & 15.95 & Highly significant \\
\cline { 1 - 3 } Post-test & 13.38 & \pm 1.81 & & \\
\hline
\end{tabular}


This implies that these demographic variables have no effect on the knowledge regarding malnutrition among mothers of under-five children, which further leads to the conclusion that these demographic variables have no significant association with the knowledge regarding malnutrition among the mothers of under-five children.

\section{Discussion}

This article discusses in detail the findings of the study interpreted from the analysis. The findings of the study are discussed in relation to the objectives, need for the study, and related literature of the study.

\section{Characteristics of Selected Demographic Variables of the Sample}

- $58 \%$ of the mothers of under-five children were in the age group of $21-25$ years

- $\quad 58 \%$ of the mothers of under-five children belonged to the Hindu religion

- $\quad 52 \%$ of the mothers of under-five children were taking a mixed diet

- $76 \%$ of the mothers were from nuclear families

- $62 \%$ of the mothers had a family income of INR 10003000 per month

- $50 \%$ of the mothers took primary education

- $92 \%$ of the mothers had one child in the family

- $88 \%$ of the children were partially immunized

- $30 \%$ of the mothers got the knowledge from mass media

\section{Assessment of Overall Pre-test Knowledge Score of Mothers of Under-five children}

According to the assessment of the overall pre-test knowledge level of the mothers of under-five children about the prevention of protein-energy malnutrition, the majority of the mothers (7 (14\%)) had average knowledge, 43 (86\%) had poor knowledge, and $0(0 \%)$ had strong knowledge.

\section{Assessment of Overall Post-test Knowledge Score of Mothers of Under-five Children}

The majority of the mothers (50 (100\%)) had average knowledge, $0(0 \%)$ had bad knowledge, and $0(0 \%)$ had good knowledge, according to the assessment of the overall posttest knowledge level of the mothers of under-five children regarding prevention of protein-energy malnutrition.

\section{Association of Pre-test and Post-test Knowledge Score}

The researcher applied paired t-test for the assessment of the effectiveness of a planned teaching programme and for the comparison of pre-test and post-test knowledge scores of the mothers of under-five children. The average knowledge score in the pre-test was 8.96 with a standard deviation of 1.32 which increased to 13.38 with a standard deviation of 1.81 in the post-test. The t-value for this comparison was 15.95 and the $p$-value was 0.00 , which was less than 0.05 , accepting research hypothesis $\mathrm{H} 1$, which states that there will be a significant difference between the pre-test and post-test knowledge scores of the mothers of under-five children.

The chi-square test was used to see the association between the demographic variables and the pre-test knowledge. For all the demographic variables, the $p$-value of the association test with knowledge was more than 0.05 .

This means that the knowledge regarding malnutrition among the mothers of under-five children is independent of these demographic variables, thereby concluding that there was no significant association of these demographic variables with the knowledge.

\section{Limitations of the Study}

- The study was limited only to the mothers of underfive children

- The study period was limited to 4-6 weeks of duration

- $\quad$ The sample size was limited to 50

- The study design was limited to a pre-experimental study

\section{Recommendation}

On the basis of the findings of the study, the following recommendations have been made:

1. An experimental study can be conducted with the control group for effective comparison.

2. A similar study can be replicated on a large sample to generalize the findings.

3. A study can be conducted by including additional socio-demographic variables.

4. A comparative study can be conducted between rural and urban settings.

5. A similar type of study can be conducted for other types of nutritional disorders.

6. A similar study can be conducted by using other educational methods like demonstration, role play, self-instructional module, information booklet etc.

\section{Conclusion}

The main conclusion through this study showed that majority of the mothers had inadequate knowledge in the pre-test and they improved to a moderate level of knowledge in the post-test. Hence, a structured teaching programme is proved to be significantly effective in improving the knowledge of mothers of under-five children regarding the prevention of malnutrition.

\section{Conflict of Interest: None}

\section{References}

1. Park K. Textbook of preventive and social medicine.18th 
ed. Banarsidas Bhanot; 205. p. 438-74.

2. Swaminathan M. Advanced TextBook of Food and Nutrition. 2nd ed. Bangalore Printing and Co Limited; 2019. p. 230, 540.

3. Kumar A, Jain AK, Mittal P, Katiyar GP. Weight and Height norms of 5-10 years old children of upper socio-economic status. Indian Pediatr. 1990;27(8):835. [PubMed] [Google Scholar]

4. Puri R, Chawla P, Mehta S. Retention of nutrition and health knowledge and practices - After an in-service training programme. Indian J Nutr Dietetics 1984; 21(12): 437-443. [Google Scholar]

5. Ghosh S. Nutrition and Child care. 2nd ed. Jaypee Brothers; 2007. p. 178.

6. Malekafzali H, Abdollahi Z, Mafi A, Naghavi M. Community based nutritional intervention for reducing malnutrition among children under five years of age in the Islamic republic of Iran. East Mediterr Health J 2000; 6(2-3): 238-245. [PubMed] [Google Scholar] 